Témoigner Témoigner. Entre histoire et mémoire

Getuigen Revue pluridisciplinaire de la Fondation Auschwitz

$127 \mid 2018$

Perpétuation de la violence après 1918

\title{
"Holocaust" (Marvin J. Chomsky) : Een terugblik op de controversiële miniserie
}

\section{Brecht Capiau}

\section{Q OpenEdition \\ 1 Journals}

\section{Édition électronique}

URL : https://journals.openedition.org/temoigner/7762

DOI : 10.4000/temoigner.7762

ISSN : 2506-6390

Éditeur :

Éditions du Centre d'études et de documentation Mémoire d'Auschwitz, Éditions Kimé

\section{Édition imprimée}

Date de publication : 1 octobre 2018

Pagination : 17-19

ISBN : 978-2-930953-076

ISSN : 2031-4183

Référence électronique

Brecht Capiau, «"Holocaust" (Marvin J. Chomsky) : Een terugblik op de controversiële miniserie», Témoigner. Entre histoire et mémoire [Online], 127 | 2018, Online op 10 février 2022, geraadpleegd op 14 février 2022. URL: http://journals.openedition.org/temoigner/7762 ; DOI: https://doi.org/10.4000/ temoigner.7762 


\section{HOLOCAUST (MARVIN J. CHOMSKY) EEN TERUGBLIK OP DE CONTROVERSIËLE MINISERIE}

FILM Op 16 april 1978 ging 'The Gathering Darkness', het eerste deel van de vierdelige miniserie Holocaust in première op de Amerikaanse zender NBC. De impact was gigantisch. Voor het eerst werd de gemiddelde Amerikaanse kijker geconfronteerd met de horror van de Jodenuitroeiing in de vorm van een televisiedrama. Toen de miniserie in januari 1979 ook in West-Duitsland werd uitgezonden, was de respons nog extremer. In Koblenz probeerden rechtse activisten zelfs de ARD-transmissietorens op te blazen om de uitzending te beletten. Veertig jaar later is de storm gaan liggen en kunnen we met een heldere blik kijken naar de serie en naar de relevantie ervan in onze tijd. We gaan ook in op de kritiek van Elie Wiesel, die de dramatisering van de Holocaust voor fictiedoeleinden 'onwaar' en 'beledigend' vond.

HOLOCAUST: EEN INTIEME FAMILIESAGA TEGEN DE ACHTERGROND VAN EEN WERELDBRAND

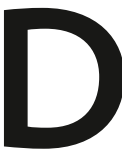

e miniserie start in 1935 met het trouwfeest van de Duitse Inga Helms en de Joodse schilder Karl Weiss. We maken ook kennis met Josef Weiss, dokter en vader van Karl, Berta Palitz, de moeder, Rudi Weiss, broer en een onstuimige voetballer, Anna Weiss, het levenslustige zusje, en tenslotte Moses Weiss, oom van Karl en apotheker in Warschau. Ook aanwezig zijn de schuchtere bakkerszoon Erik Dorf, de familie van Inga en enkele nazi's. Het is de eerste en meteen ook de laatste keer dat we de belangrijkste personages in harmonie zien met zichzelf en met de ander. Zoals de titel van de eerste aflevering al laat vermoeden, trekken er algauw donderwolken samen en breken barre tijden aan. Het was een goede beslissing van de makers van deze serie om de personages op te splitsen en naar andere locaties te sturen zodra 'het Jodenprobleem' urgenter wordt. Zo

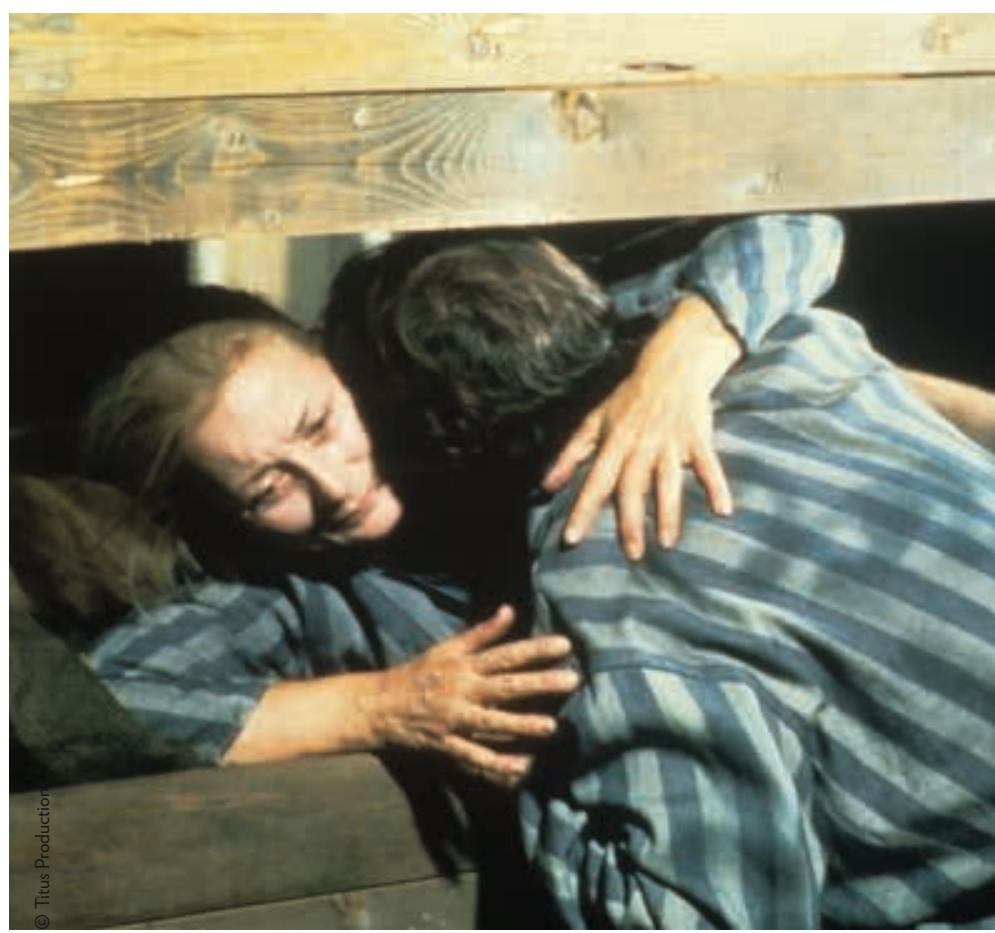


$\bullet$ ontstaat een caleidoscopisch overzicht van de verschilende aspecten van de Holocaust.

Oorlog brengthet techtse, mar ool hetbeste in de mens nar boven. Bij sommige perot Moses Weiss is de tran ontwikkelt zich van een parifst to ontwikkelt zich van een pacifst tot een uiterst gedreven verzetsman die niet bang is on de wapens op te ren ter hij al de minder of ne log zijn missie om de zwakken bij te sta on alleen morlog zijn missie on de zwakken bij te staan alleen maar zich door Helo de orlog slat, is bewonderenswardig. cher is voora zerhaallijn van Inga Helms, gespeeld door Meryl Streep, een 'oorKarl Streep die zoeknaar haar gevangengenomen man . melodramatische vertolkngen, verstikt menig scèn

Wat de beeldregie betreft staat de serie mijlenve van wat de modale kijker vandaag gewend is. Je moet Jolocaust dason jaren zeventigin het achterhout. Ano 2018 komt het geher traag, stifen sterk gedateerd over. Holocast is pisu tisch, maar het scoort welgoede punten voor de manie waarop een aantal historische gebeurtenissen geporte laten uitmaken van Holocaust - er wordt uitgebreid

ingezoomd op de Joodse strijd tijdens de opstand in het getto van Warschau en op de Joodse partizanensewe Jood' snel one - wordt de mythe van de 'passieve Jood snelonthrood opnieuw aandachtbestedenaan verzetin de fim Defiance van Edward Zwick. Op da lak was de miniserie zijn tijd dus ver vooruit.

ELIE WIESEL'S KRITISCHE BESPIEGELINGEN OVER HOLOCAUST

ElieWiesel(1928-2016), eenvandemeestberoemde Holocaustoverlevenden en ook Nobelprijswinnaar Dag, een trilogie va boek vertelt ov aijn wan boeken waarin hij uitgebreid vitz over zijn ervangen in de kampen van Auschwitz en Buchenwal. Op 16 april 1978 verscheen naar aanioing vande uitzendingvan Holocaust in de Times Staten Times wan inis in inhoud van de tekst doen vermoeden dat Wiesel het mees wa 1moest wacht

Wooit meteen de knuppel in het hoenderhok door te stellen dat de televisieproductie een belediging s voor diegenen die omkwamen en voor diegenen die serie een ontogisch even ogen transformeert de

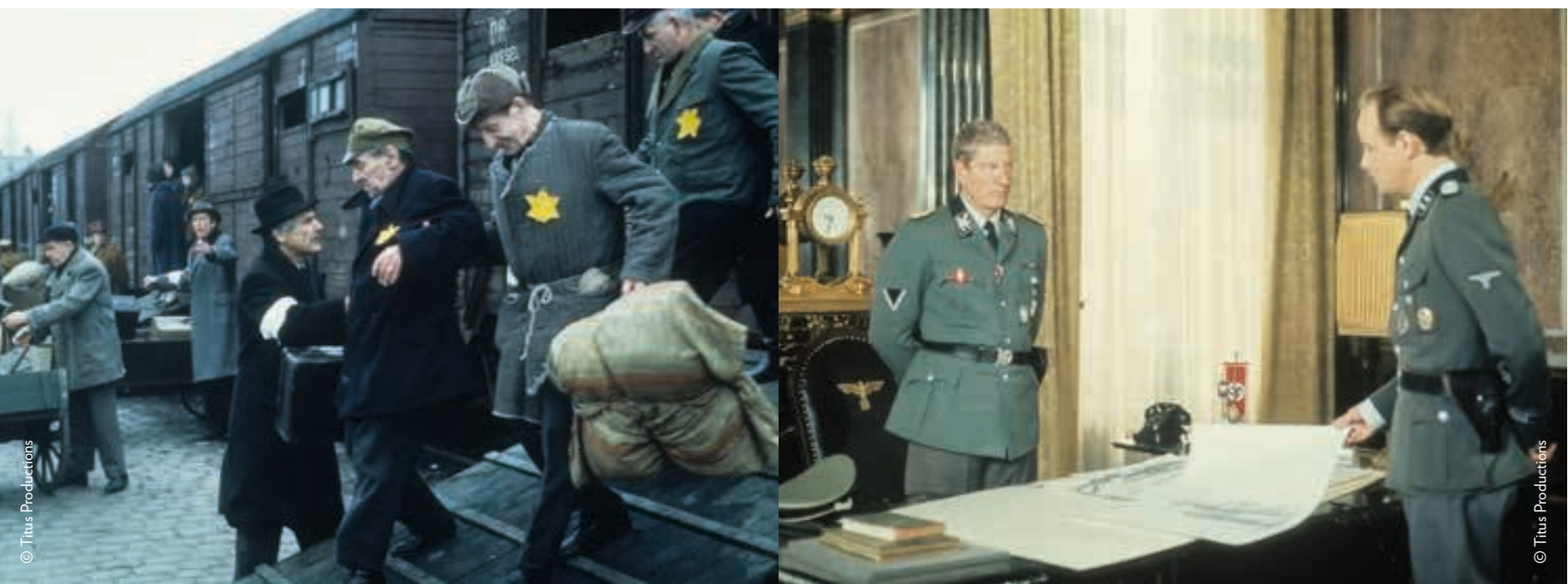

Hij vindt het immoreel dat alles wordt getoond, ook hoe de slachtoffers stierven. Bovendien is volgens hem de Holocaust uniek: 'The ultimate event, the ultimate mystery, never to be comprehended or transmitted. Only those who were there know what it was; the other will never know.' Die uitspraak is uiteraard problematisch. Wiesel hypothekeert hiermee het proces va getuigens in geschied re te veel ban. Wiesel vest rie te veel balanceert tussen 'semi-feit' en 'semi-fictie' che spelen. In dit verband vraagt hij zich af warom

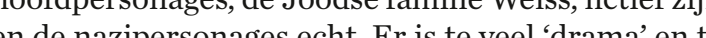
en de nazipersonages echt. Er is te veel 'drama' en

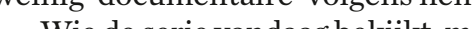

ie derisel op dat er wel hél veel gebeurtenissen worden behangrondig te doen Kristlhacht, de onvijuillige euthgrondig te doen. Kristallnacht, de onvijwillige euthanasie van psychiatische patienten in het Hadamar het gerium, de slachting bij Babi Yar, de opstand in is de familie Weiss telke op betroken. Je kan is de familie Weiss telkens betrokken. Je kan perfect argumenteren dat je onmogelijk álle aspecten van de kolocaust kan vatten in én televisieserie, boek of kunstwerk. Het is on wellicht in hun ijver dat een sere die Hos ducht wellicht in hun ijuc dat eerije verhallijnen moet oh dand Titus Prodions, de productientedoen. Jekanhet Titus Productions, de productienaatschappij achter Holocaust, gezien de tijdscontext ook niet echt kwalijk nemen. Televisiefictie was eind jaren zeventig op was, net as Roots uit 1977 dat de slaveriij oncer was, net als Roots uit 1977 dat de slavernij onder de loep nam, op dat vlak didenjk pionierswerk, met all voor-en nadelen vandien.

he caust'zonder de enkel academici en historici gebruikten. In de Canvasdocument Holocaust kort an uit de popuire cultuur die de bewustwo vorbeeld de Jodenuitroeiing een duwtje in de ven De serie-televisiefictie voor de rug heeft gegeven. De serie - televisiefictie voor den breed publiek was met andere woorden een middelom een specifiek doel - aandacht voor de Holocaust - te bereiken. De neveneffecten. Een geëmotioneerde Jimmy Carter, de toenmalige president van de Verenigde Staten, ichtte prompt een presidentiële commissie op die de Holocaust moest onderzoeken. In haar eindrapport suggereerde de commissie dat het een goed ide

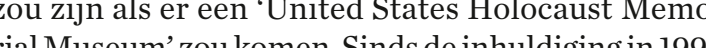

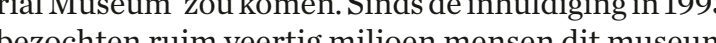
in Washing i dan weer een startpunt om de verhalen van de histoVide Archive for Holocast Testin. Het Fortunof Vidoo Archive for te latocaust Testimonies, dat door Video Archive for Holocin erzameld.

De vrees van Wiesel dat het grote publiek de Holocaust enkel zal kennen door de miniserie is echte volledig ongegrond. Sindsdien zijn er tal (an film coals Schindler sList (1993) en Son of Saul (2015), uitgebracht die zo slim waren on slechts een specifiek (e) identificeren. Deze films zullen op langer mee ka identificeren. Deze films zullen op langere termijn ren maal zijh het stukjes die de puzzel, die Holocaust heet. vervol digen. Holocaust noest eind jaren zeventig vooral dienen als stormram on de poorten van de kans is dac ook zeer klein dat er oot een 'ren. De koms is dan ook zeer klein dat er ooit een 'remake' is vand is vandaag slechts een misklik verwijderd van goed Brecht Capiau

$\rightarrow$ Bibliografie

$\triangle$ Eli Wiesel, 'Trivializing the Holocaust: Semi-Fact and Semi-Fiction," The New York Times, 16 april 1978, https:// www.nytimes.com/1978/04/16/archives/tv-view-trivializingthe-holocaust-semifact-and-semifiction-tv-view.html

(geraadpleegd 1 juni 2018).

Meer weten

$\widehat{A}$ Holocaust van Marvin J. Chomsky (1978) Met Mery Streep (Inga Helms), Michael Moriarty (Erik Dorf) 